\title{
Bisferiens Peaks in the Radial Artery Pressure Wave in Newborn Infants: A Sign of Patent Ductus Arteriosus
}

\author{
MAGDALENA GEVERS, HUIBERT R. VAN GENDERINGEN, KARIN VAN DER MOOREN, \\ HARRIE N. LAFEBER, WILLEM W. M. HACK, AND NICO WESTERHOF \\ Departments of Pediatrics-Neonatology, Clinical Physics and Physiology, Free University Hospital, \\ Amsterdam, The Netherlands [M.G., H.R.V.G., K.V.D.M., H.N.L., N.W.] and Department Pediatrics, \\ Medical Centre Alkmaar, Alkmaar, The Netherlands [W.W.M.H.]
}

\section{ABSTRACT}

Previously, we found evidence that radial artery pressure wave forms in newborns represent central aortic wave forms, provided that pressure is measured with adequate accuracy. Therefore, we postulated that the neonatal radial artery wave form, like the adult aortic wave form, may contribute to cardiovascular diagnosis. We investigated whether radial artery wave forms in infants suffering from patent ductus arteriosus (PDA) are different from the wave forms as seen without the presence of PDA. We studied 34 newborn infants with a radial artery line and with the possible clinical diagnosis of PDA with left-to-right shunt. On the basis of echocardiographic examination to assess PDA, these infants were divided in two groups: infants with PDA $(n=24)$ and without PDA $(n=10)$. In 15 out of 24 infants with PDA, recordings were repeated after ductal closure. Blood pressure measurement was performed with a high fidelity cathetermanometer system using a tip-transducer (natural frequency 95 $\mathrm{Hz}$, damping coefficient 0.15 ). Contour analysis was performed by describing morphology of the waves during PDA and without PDA. In 23 out of 24 infants with PDA, a pulsus bisferiens was present: two peaks separated by a deep cleft. The average pressure difference between the first pressure peak and the cleft $\left[\Delta \mathrm{P}_{\text {peak } 1}\right]$ was $0.35 \pm 0.19 \mathrm{kPa}$, and the average difference between the cleft and the second pressure peak $\left[\Delta \mathrm{P}_{\text {peak } 2}\right]$ was $0.44 \pm 0.23 \mathrm{kPa}$. The ratio of mean magnitude of $\Delta \mathrm{P}_{\text {peak } 1}$ and $\Delta \mathrm{P}_{\text {peak } 2}$ was $0.81 \pm 0.26$. None of the 10 infants without PDA showed pulsus bisferiens. In 13 out of 14 infants with pulsus bisferiens during PDA and studied again after ductal closure, this twin peaks contour had disappeared. Results strongly indicate that the presence of a bisferiens pressure pulse is a sign of PDA with hemodynamically significant left-to-right shunt. (Pediatr Res 37: 800-805, 1995)
SAP, systolic arterial pressure
DAP, diastolic arterial pressure
MAP, mean arterial pressure
PP, pulse pressure
PDA, patent ductus arteriosus

In adults, the arterial pressure wave form has been studied extensively, and it has long been recognized that the arterial pressure wave form may contribute to cardiovascular diagnosis (1-4). Regarding clinical application of the arterial pulse tracing, a thorough overview can be found in Tavel (5). In neonates, however, the importance of the pressure wave form has received far less attention.

To obtain accurate pressure recordings in neonates, we developed a technique for pressure measurement through radial artery catheters on the basis of a tip-manometer (6). With this technique, accurate measurement of blood pressure values and wave forms has become available in neonatal clinical practice. Previously, we described the radial artery pressure wave form

Received April 12, 1994; accepted December 29, 1994.

Correspondence: M. Gevers, M.D., Department Paediatrics-Division Neonatology, Free University Hospital, De Boelelaan 1117, $1081 \mathrm{HV}$ Amsterdam, The Netherlands. in the critically ill newborn: we found evidence that radial artery wave forms in these newborns represent central ascending aortic wave forms (7). A representative radial artery wave form of a newborn infant is shown in Figure 1. We postulate that the contour of the radial pressure wave in the newborn, like the central wave form in adults, may provide information regarding the cardiovascular state, such as the presence of a PDA. Therefore, we investigated whether radial artery pressure wave forms in infants suffering from PDA are different from pressure wave forms seen in those without shunting through a PDA.

Although aortic and peripheral arterial flow wave form studies during PDA in infants have been performed in the past (8-11), accurately recorded radial artery pressure wave forms in infants suffering from a left-to-right shunt through the ductus arteriosus have not been described. 


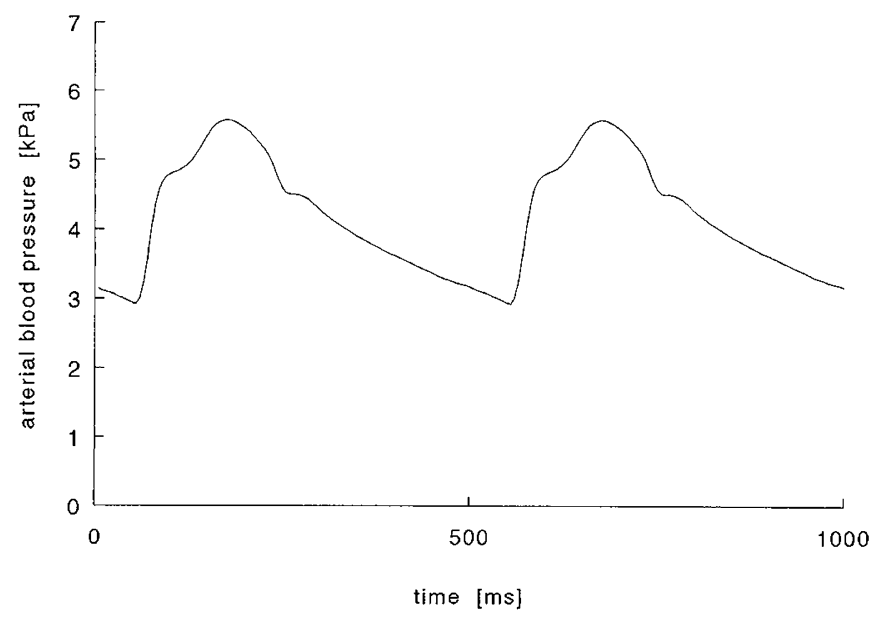

Figure 1. Radial artery wave as usually seen in the newborn. A secondary systolic wave, i.e. the inflection point can be seen in the upstroke, a short and sharp incisura can be seen in the downstroke of the wave.

\section{METHODS}

Patients. Thirty-four newborn infants admitted for intensive care and meeting the following criteria were included: 1 ) requirement of radial artery cannulation for clinical purposes (frequent blood sampling and blood pressure monitoring) and 2) the possible clinical diagnosis of ductal patency with leftto-right shunt. Infants suffering from cardiac anomalies or from ductal patency with right-to-left shunt or treated with vasoactive agents were excluded. Possible ductal patency was judged by the clinical staff, and echocardiography was performed to assess ductal patency. On basis of echocardiographic examination the infants were assigned to two groups: infants with PDA ( $n=24$, referred to as group $\mathrm{I}_{\mathrm{PDA}}$, gestational age 31.3 $\pm 3.9 \mathrm{wk}$, birth weight $1378 \pm 882 \mathrm{~g}$ ), and infants without PDA ( $n=10$, referred to as group II, gestational age $29.5 \pm$ $4.6 \mathrm{wk}$, birth weight $1337 \pm 925 \mathrm{~g}$ ). In group $\mathrm{I}_{\mathrm{PDA}} 15$ out of 24 infants suffered from idiopathic respiratory distress syndrome, three suffered from pneumonia, and four infants suffered from both. In group II diagnosis on admission was idiopathic respiratory distress syndrome in six and pneumonia in two out of 10 infants. Other diagnoses were asphyxia and meconium aspiration. All infants were mechanically ventilated. Mean postnatal age of infants in group I was $2.0 \pm 0.8 \mathrm{~d}$ and in group II $3.3 \pm 1.7 \mathrm{~d}$. Immediately after echocardiography, arterial pressure recordings were made. In infants with PDA (group $\mathrm{I}_{\mathrm{PDA}}$ ) treatment was given, and echocardiography was performed daily, until ductal closure was confirmed. After ductal closure, additional blood pressure recordings were obtained ( $n=15$, referred to as group $\left.\mathrm{I}_{\mathrm{Clos}}\right)$. Infants with PDA were excluded from further studies when a right-to-left shunt had developed, when vasoactive agents were used (apart from indomethacin), or when the arterial line was removed for clinical reasons due to reduced oxygen dependence or due to the presence of blood clots in the arterial line.

The treatment regimen for infants with PDA was fluid restriction and/or indomethacin, unless contraindicated. The treatment scheme for indomethacin was an initial dose of 0.2 $\mathrm{mg} / \mathrm{kg}$ i.v.; if unsuccessful, a second dose of $0.1 \mathrm{mg} / \mathrm{kg} 24 \mathrm{~h}$ after the first dose and, if necessary, a third dose of $0.1 \mathrm{mg} / \mathrm{kg}$ $48 \mathrm{~h}$ after the initial treatment. If treatment with indomethacin was still unsuccessful after the third dose or in cases of contraindications to indomethacin therapy, surgical closure was performed. Therapy for PDA was fluid restriction alone in three infants, fluid restriction with indomethacin treatment in 11 infants, and surgical closure in one infant. Mean postnatal age at confirmation of ductal closure in the infants was $3.6 \pm$ $1.3 \mathrm{~d}$.

The study was approved by the ethical committee of our hospital and parental informed consent was obtained.

Materials and measurements. Blood pressure measurement recordings of $2 \mathrm{~min}$ were performed with a high fidelity catheter-manometer system, consisting of a side hole tiptransducer (MTC, Honeywell, Pleasantville, NY), a 24-gauge Teflon catheter (Neoflon, length $16 \mathrm{~mm}$, Ohmeda, Helsingborg, Sweden), and a transparent three-way stopcock (Ohmeda, Helsingborg, Sweden). The tip-transducer was connected by Luer-Lock to one end of the stopcock. Another end of this stopcock was connected to the catheter. The system was shown to have a uniform frequency response $( \pm 3 \mathrm{~dB})$ up to at least $50 \mathrm{~Hz}$ (natural frequency $95 \mathrm{~Hz}$, damping coefficient 0.15). Static accuracy of the system was tested against a column of mercury between 0 and $16.0 \mathrm{kPa}$. The system is shown in Figure 2, and a complete description of the tiptransducer system is found in Hack et al. (6). The remaining end of the three-way stopcock was connected to the clinically used fluid-filled manometer system for continuous flushing, for blood sampling, and for usual pressure monitoring as described previously (12). The high fidelity measurement system was connected to a physiologic monitor (Hewlett Packard 78834A, Andover, MA), which was modified to pass signals up to $30 \mathrm{~Hz}$ ( $75 \mathrm{~Hz}$ Bessel filter, $36 \mathrm{~dB} /$ octave). This pressure signal was digitized by a 12-bit A/D converter (Keithly DAS 16 Metrabyte, Taunton, MA) at a sample rate of $200 \mathrm{~Hz}$ and was stored on computer disk using a multichannel registration programme (CDAI, University Hospital Rotterdam, The Netherlands). An off-line analysis algorithm, written in the signal processing language POLY (Inspector Research Systems, Amsterdam, The Netherlands), was implemented on the computer, reducing the data to beat-to-beat values for systolic, diastolic and mean blood pressure. Care was taken to recognize and reject measurement artefacts.

Echocardiography was performed with a Duplex scanner (Hewlett Packard 77020A) using a 5-MHz short focus probe. Ductal patency was established by direct imaging of the ductus with color flow, pulsed Doppler, or both. The ductus was regarded to be closed when ductal flow was absent.

Data analysis. In each pressure recording, one representative, stable wave was selected at random for contour analysis, i.e. a wave where the diastolic pressure at the beginning and end of the beat deviated less than $5 \%$. A stable wave was selected to avoid a bias in the analysis due to differences between the begin and end diastolic value, which, among others, may be due to mechanical ventilation.

Contour analysis was performed by describing morphology of the wave: peaks and incisuras in the wave were described in time $(\mathrm{t})$ in milliseconds and pressure $(\mathrm{P})$ in $\mathrm{kPa}$ as shown in 


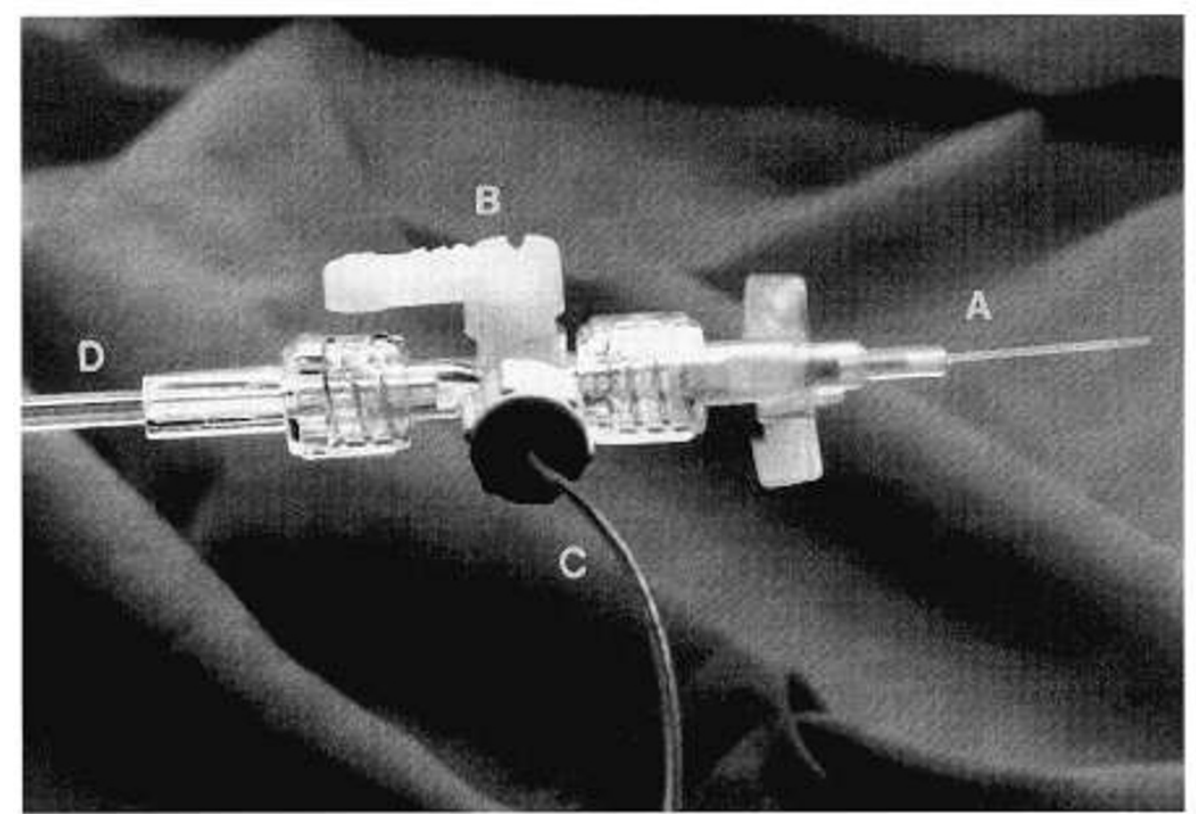

Figure 2. The high fidelity catheter-manometer system. $A$, catheter; $B$, transparent stopcock; $C$, tip-manometer connected to the monitor; $D$, extension tube connected to the fluid-filled routinely used catheter-manometer system.

Figure 3, $A$ and $B$. If two peaks during systole were present in the wave, the pressure differences between these peaks and the cleft were determined $\left[\Delta \mathrm{P}_{\text {peak } 1}\right.$ and $\left.\Delta \mathrm{P}_{\text {peak } 2}\right]$ (see Fig. $3 A$ ). If the magnitude of $\Delta \mathrm{P}_{\text {peak } 1}$ in relation to $\Delta \mathrm{P}_{\text {peak2 }}$ was more than 0.4 and less than 1.6, the wave was designated as pulsus bisferiens. For comparison with morphometric data in pulsus bisferiens, contour analysis in group II and group $\mathrm{I}_{\text {CLOS }}$ was also performed, for identification of the parameters determined in pulsus bisferiens (see Fig. $3 B$ ). $\mathrm{P}_{\text {peak } 1}$ in the normal waves was defined as the point in the upstroke of the wave where the derivative reached a minimum value (see Fig. $3 B$ ).

In addition, the slope of the upstroke and the decay time ( $\tau$, defining the rate of decay of the pressure in diastole) were calculated. It was assumed that pressure in diastole decays exponentially. The time constant of this decay is calculated as given in the "Appendix."

Blood pressure values and the results of the contour analysis were compared between infants suffering from PDA in group I and infants without PDA in group II on one hand and with infants after ductal closure on the other hand, with the multivariate Hotelling's $T$ test, thereby controlling for multiple comparisons. In case of a significant Hotelling's $T$ test $(p<$ 0.05 ), univariate analysis was performed to test the significance of the individual parameters (paired and unpaired $t$ test).

\section{RESULTS}

$\mathrm{SAP}, \mathrm{DAP}, \mathrm{MAP}$, and PP in infants of groups $\mathrm{I}_{\mathrm{PDA}}, \mathrm{I}_{\mathrm{CLOS}}$, and II are shown in Table 1 . Differences in these parameters between the groups were not significant.

With PDA, blood pressure wave forms in 23 out of 24 infants were clearly different from those observed in the radial artery without PDA. With PDA, a pulsus bisferiens, two peaks clearly separated by a deep cleft, was present both during inspiration and during expiration of the patient. An example of the radial artery pressure wave form as found in 23 infants suffering from PDA is shown in Figure $3 A$. In one out of 24 infants there was no pulsus bisferiens during PDA. None of the 10 infants without PDA (group II) showed pulsus bisferiens; a typical wave form is presented in Figure $3 B$.

Morphology of the wave during PDA can be described in detail using variables as shown in Figure $3 A$. A complete description of the pulsus bisferiens in the 23 infants is shown in Table 2. As can be seen, the mean pressure difference between the first pressure peak and the cleft $\left[\Delta \mathrm{P}_{\text {peak } 1}\right]$ was 0.34 $\pm 0.19 \mathrm{kPa}$, the mean pressure difference between the cleft and the second pressure peak $\left[\Delta \mathrm{P}_{\text {peak } 2}\right]$ was $0.44 \pm 0.23 \mathrm{kPa}$. $\Delta \mathrm{P}_{\text {peak1 }}$ was always greater than $0.08 \mathrm{kPa}$ and $\Delta \mathrm{P}_{\text {peak2 } 2}$ was always greater than $0.19 \mathrm{kPa}$. The mean pressure-difference between $\Delta \mathrm{P}_{\text {peak } 1}$ and $\Delta \mathrm{P}_{\text {peak } 2}$ was $0.09 \pm 0.13 \mathrm{kPa}$. The ratio of mean magnitude of $\Delta \mathrm{P}_{\text {peak } 1}$ and $\Delta \mathrm{P}_{\text {peak } 2}$ was $0.81 \pm 0.26$.

Follow-up until the ductus was closed was carried out in 14 of these 23 infants with a pulsus bisferiens. (Nine infants were not considered for follow-up because of treatment with vasoactive agents or due to arterial line removal.) After ductal closure, pulsus bisferiens in the radial artery pressure wave had disappeared in 13 out of 14 infants. Further studies of the single infant still showing pulsus bisferiens after ductal closure could not be performed.

For comparison with the morphometric data in pulsus bisferiens, contour analysis in group II and group $\mathrm{I}_{\mathrm{CLOS}}$ was performed, for identification of the parameters determined (see Fig. 3B).

Results of the contour analysis in group II and the differences between the waves during PDA (group $\mathrm{I}_{\mathrm{PDA}}$ ) and without PDA (group II) are shown in Table 2. Hotelling's $T$ test showed a significant difference between the contour profiles of group $\mathrm{I}_{\mathrm{PDA}}$ and group II. As can be seen, there was no significant difference between timing of the first peak $\left(t_{1}\right)$ in group $\mathrm{I}_{\mathrm{PDA}}$ and in group II, but the second peak $\left(\mathrm{t}_{2}\right)$ during PDA appeared significantly later (on the average $2 \%$ of the 

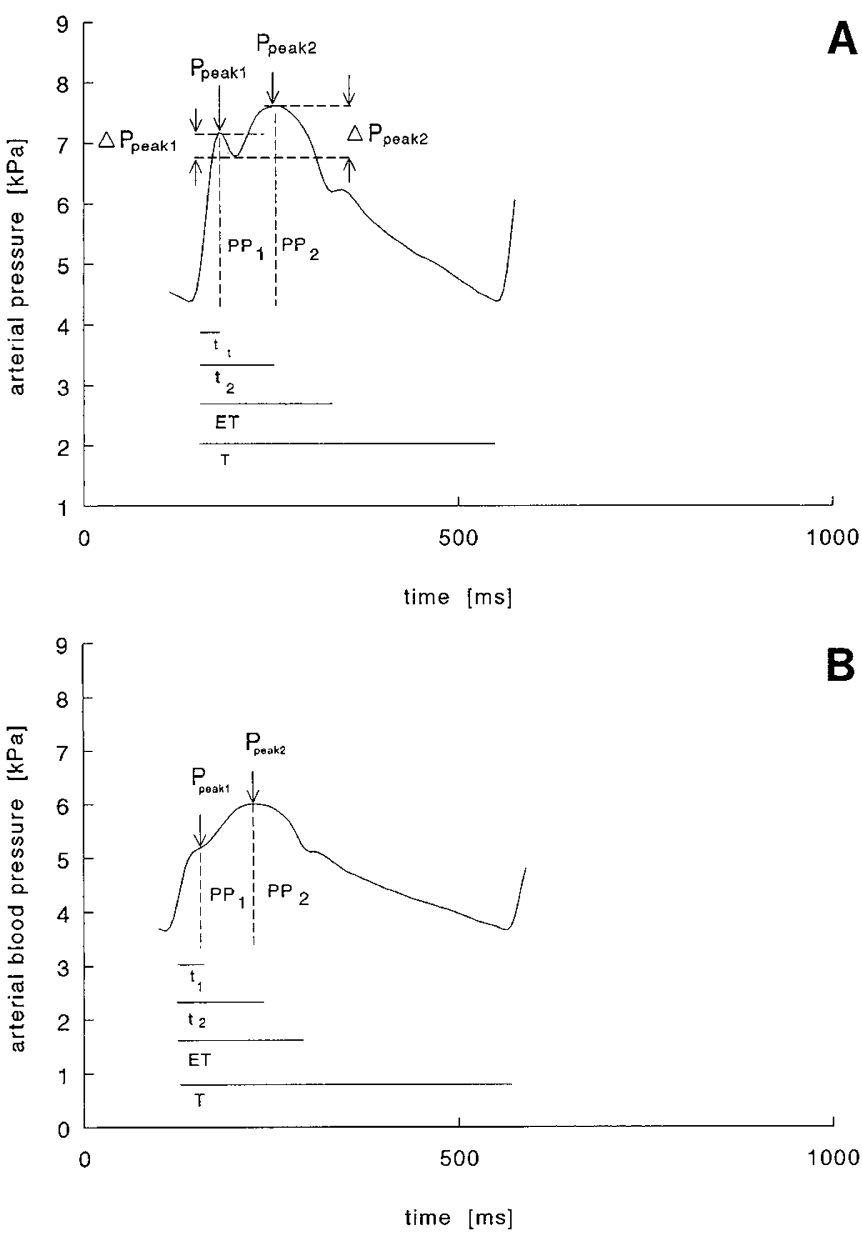

Figure 3. $A$, Radial artery wave form showing pulsus bisferiens during PDA, illustrating parameters for describing morphology of the wave. $\Delta \mathrm{P}_{\text {peak } 1}=$ pressure of peak 1 in relation to the cleft, $\Delta \mathrm{P}_{\text {pcak } 2}=$ pressure of peak 2 in relation to the cleft, $\mathrm{PP}_{1}=\mathrm{PP}$ between $\mathrm{P}_{\text {peak } 1}$ and diastole, $\mathrm{PP}_{2}=\mathrm{PP}$ between $\mathrm{P}_{\text {peak } 2}$ and diastole, $\mathrm{t}_{1}=$ time at peak $1, \mathrm{t}_{2}=$ time at peak $2, \mathrm{ET}=$ ejection time, $\mathrm{T}=$ heart period. $B$, Radial artery wave form without the presence of PDA, illustrating parameters for describing morphology of the wave. $t_{1}=$ time at peak $1, \mathrm{t}_{2}=$ time at the systolic peak, $\mathrm{PP}_{1}=$ pressure difference between $\mathrm{P}_{\text {peak } 1}$ and diastole, $\mathrm{PP}_{2}=\mathrm{PP}$ between $\mathrm{P}_{\text {peak2 } 2}$ and diastole, $\mathrm{ET}=$ ejection time, $\mathrm{T}=$ heart period.

Table 1. Blood pressure data in infants of group $I_{P D A}$, group $I_{C L O S}$ and group II

\begin{tabular}{lcccc}
\hline $\begin{array}{c}\text { Pressure } \\
(\mathrm{kPa})\end{array}$ & $\begin{array}{c}\text { Group } \mathrm{I}_{\mathrm{PDA}} \\
(n=24)\end{array}$ & $\begin{array}{c}\text { Group } \mathrm{I}_{\mathrm{CLOS}} \\
(n=15)\end{array}$ & $\begin{array}{c}\text { Group II } \\
(n=10)\end{array}$ & \\
\hline SAP & $6.82(0.90)$ & $7.21(0.92)$ & $7.28(0.90)$ & $\mathrm{NS}^{a}$ \\
DAP & $4.08(0.82)$ & $4.31(0.82)$ & $4.34(0.85)$ & $\mathrm{NS}$ \\
MAP & $5.41(0.82)$ & $5.72(0.89)$ & $5.69(0.84)$ & NS \\
PP & $2.67(0.48)$ & $2.83(0.41)$ & $2.93(0.48)$ & NS \\
\hline
\end{tabular}

Values are mean and SD.

${ }^{a} \mathrm{NS}$, differences between the groups were not significant.

heart period, which equals $8 \mathrm{~ms}$ ) than $t_{2}$ in the wave forms in group II. The PP of the first peak $\left(\mathrm{PP}_{1}\right)$ during PDA was 0.43 $\mathrm{kPa}$ larger than the $\mathrm{PP}_{1}$ in the wave forms without the presence of PDA and $\mathrm{PP}$ of the second peak $\left(\mathrm{PP}_{2}\right)$ during PDA was 0.41 $\mathrm{kPa}$ smaller than $\mathrm{PP}_{2}$ in control wave forms. In addition, contour analysis revealed that ejection time (ET) in relation to the heart period $(\mathrm{T})$ was $4 \%$ of the heart period longer $(16 \mathrm{~ms})$ in group $\mathrm{I}_{\mathrm{PDA}}$ as compared with group II.
Table 2. Morphologic data of radial artery pressure wave forms in infants with PDA (group $I_{P D A}$ ), showing pulsus bisferiens and in infants without PDA (group II)

\begin{tabular}{lcc}
\hline & $\begin{array}{c}\text { Group } \mathrm{I}_{\text {PDA }} \\
(n=23)\end{array}$ & $\begin{array}{c}\text { Group II } \\
(n=10)\end{array}$ \\
\hline $\mathrm{T}(\mathrm{ms})$ & $421(38)$ & $424(50)$ \\
$\mathrm{t}_{1} / \mathrm{T}$ & $0.11(0.02)$ & $0.10(0.02)$ \\
$\mathrm{t}_{2} / \mathrm{T}$ & $0.28(0.03)$ & $0.26(0.03)^{a}$ \\
$\mathrm{PP}_{1}(\mathrm{kPa})$ & $2.53(0.52)$ & $2.06(0.53)^{a}$ \\
$\mathrm{PP}_{2}(\mathrm{kPa})$ & $2.62(0.49)$ & \multicolumn{2}{c}{$3.04(0.44)^{a}$} \\
$\Delta \mathrm{P}_{\text {pcak1 }}(\mathrm{kPa})$ & $0.35(0.19)$ & \\
$\Delta \mathrm{P}_{\text {peak2 } 2}(\mathrm{kPa})$ & $0.44(0.23)$ & \multicolumn{2}{|c}{} \\
$\Delta \mathrm{P}_{\text {peak1 }} / \Delta \mathrm{P}_{\text {peak2 }}$ & $0.81(0.26)$ & \multicolumn{2}{c}{$0.46(0.02)^{a}$} \\
$\mathrm{ET} / \mathrm{T}$ & $0.50(0.05)$ & \multicolumn{2}{c}{$677(140)$} \\
$\tau(\mathrm{ms})$ & $737(232)$ & \multicolumn{2}{c}{. }
\end{tabular}

Values are mean and SD. For abbreviations, see Figure $3, A$ and $B . \tau=$ rate of decay of pressure during diastole.

${ }^{a}$ Significant difference between values for group $\mathrm{I}_{\mathrm{PDA}}$ and group II: $p<$ 0.05 with a Hotelling's $T$ test: $p<0.05$.

Results of comparison between radial artery waves during PDA (group $I_{\text {PDA }}$ ) and pressure waves in the same infants after ductal closure (group $\mathrm{I}_{\mathrm{CLOS}}$ ) are shown in Table 3. Hotelling's $T$ test showed a significant difference between the contour profiles of group $\mathrm{I}_{\mathrm{PDA}}$ and group $\mathrm{I}_{\mathrm{CLOS}}$. None of the pressure waves were classified as pulsus bisferiens, although three infants showed a small pressure decrease after the $\mathrm{P}_{\text {peak } 1}$ : as the ratio $\Delta \mathrm{P}_{\text {peak } 1} / \Delta \mathrm{P}_{\text {peak } 2}$ of the waves of these three infants was 0.22 ( \pm 0.12 ), the waves were not designated as pulsus bisferiens. As can be seen, no difference was found between $\mathrm{PP}_{1}$ during PDA and $\mathrm{PP}_{1}$ after ductal closure. The $\mathrm{PP}_{2}$ during PDA was $0.45 \mathrm{kPa}$ smaller than $\mathrm{PP}_{2}$ after ductal closure.

\section{DISCUSSION}

During PDA with left-to-right shunt radial artery pressure wave forms in 23 of 24 infants were different from those normally observed: two peaks clearly separated by a deep cleft or pulsus bisferiens were present in systole. None of the 10 infants without a shunt through the ductus showed a pulsus bisferiens in the radial artery wave. In 13 of 14 infants with

Table 3. Morphologic data of radial artery pressure wave forms in infants with pulsus bisferiens during PDA (group $\left.I_{P D A}\right)$ and without pulsus bisferiens after ductal closure (group $I_{C L O S}$ )

\begin{tabular}{|c|c|c|}
\hline & $\begin{array}{c}\text { Group } \mathrm{I}_{\text {PDA }} \\
(n=13)\end{array}$ & $\begin{array}{l}\text { Group } \mathrm{I}_{\mathrm{CLOS}} \\
(n=13)\end{array}$ \\
\hline $\mathrm{T}(\mathrm{ms})$ & $427 \quad(39)$ & $432 \quad(45)$ \\
\hline$t_{1} / T$ & $0.12(0.02)$ & $0.12(0.02)$ \\
\hline$t_{2} / T$ & $0.28(0.03)$ & $0.27(0.03)$ \\
\hline $\mathrm{PP}_{1}(\mathrm{kPa})$ & $2.47(0.51)$ & $2.49(0.48)$ \\
\hline $\mathrm{PP}_{2}(\mathrm{kPa})$ & $2.59(0.43)$ & $3.03(0.45)^{a}$ \\
\hline$\Delta \mathrm{P}_{\text {peak } 1}(\mathrm{kPa})$ & $0.32(0.13)$ & \\
\hline$\Delta \mathrm{P}_{\text {peak2 }}(\mathrm{kPa})$ & $0.44(0.22)$ & \\
\hline$\Delta \mathrm{P}_{\text {peak } 1} / \Delta \mathrm{P}_{\text {peak } 2}$ & $0.80(0.30)$ & \\
\hline $\mathrm{ET} / \mathrm{T}$ & $0.50(0.04)$ & $0.46(0.05)$ \\
\hline$\tau(\mathrm{ms})$ & $748 \quad(215)$ & $745 \quad(148)$ \\
\hline
\end{tabular}

Values are mean and SD. For abbreviations, see Figure $3, A$ and $B . \tau=$ rate of decay of pressure during diastole.

${ }^{a}$ Significant difference between values for group $\mathrm{I}_{\mathrm{PDA}}$ and group $\mathrm{I}_{\mathrm{CLOS}}: p<$ 0.005 with a Hotelling's $T$ test: $p<0.05$. 
pulsus bisferiens during PDA and studied again after ductal closure, pulsus bisferiens had disappeared after ductal closure.

The suitability of pressure wave form analysis to diagnose PDA correctly can be assessed by the parameters sensitivity and specificity. In this study, the sensitivity, which is the proportion of true positives that are correctly identified as such is $23 / 24=0.96$ and the specificity, which is the proportion of true negatives correctly identified as such is $10 / 10=1$. Therefore, the results of this study strongly suggest that pulsus bisferiens during systole in the radial artery wave is a sign of PDA with left-to-right shunting. Regarding the above mentioned specificity of the pulsus bisferiens in this study, it is important to realize that only infants with PDA entered the study and that infants with cardiovascular anomalies were excluded: it may be possible that pulsus bisferiens also occurs in other cardiovascular abnormalities.

As shown in Tables 2 and 3, the moment of appearance of the first peak $\left(t_{1}\right)$ in pulsus bisferiens was not different from that in normal wave forms. The moment of appearance of the second peak $\left(t_{2}\right)$ in group $I_{P D A}$ was at the same time as the normal peak in groups $\mathrm{I}_{\mathrm{CLOS}}$, but $2 \%$ of the heart period (which equals $8 \mathrm{~ms}$ ) later compared with the infants' waves in group II. As significant differences were found between PP values at comparative points of time in the waves, the main reason for appearance of pulsus bisferiens seemed to be the changed ratio of magnitudes of $\mathrm{PP}_{1}$ and $\mathrm{PP}_{2}$ in the normal and bisferiens wave forms. A delay in appearance of the second peak may generate a double peak contour. As can be seen from Tables 2 and 3, differences between the waves are limited to systole: no significant difference in the decay time in diastole was found between infants with and without PDA.

SAP, DAP, and MAP were not significantly lower in infants with PDA (group $\mathrm{I}_{\mathrm{PDA}}$ ) than in infants without PDA (group II) and were not increased after ductal closure. No significant changes in PP were found. Classical signs of PDA as full pulses, widened PP, a high parasternal systolic murmur, and low MAP are criteria for PDA in older infants and children (13). Several studies focusing on blood pressure and PP during PDA in preterm infants during the first days of life have been reported. Evans and Moorcraft (14) found that both SAP, DAP and MAP were not lower in infants weighing 1000-1500 g with PDA compared with infants without PDA. Differences in SAP, DAP, and MAP were found in infants weighing less than $1000 \mathrm{~g}$ with PDA compared with infants without PDA $(14,15)$. An absence of differences in $\mathrm{PP}$ in preterm infants with and without PDA in the first postnatal week has been reported $(14,15)$. Recently, blood pressure after indomethacin treatment for PDA was found to increase steadily during the first $3 \mathrm{~d}$ after treatment (16). Regarding the study population and the time points of our measurements, our observations are in agreement with these results.

The results of our study strongly indicate that the presence of a bisferiens pressure pulse is a sign of PDA. These findings are in accordance with a few single cases which have been reported regarding observations of bisferiens pressure pulses in the aorta or carotid artery in PDA (17-19). Whereas these examples of bisferiens pulses during PDA are observed in the aorta or carotid artery, we demonstrated in this study the presence of twin peaks in the radial artery wave. Inasmuch as we suppose that radial artery wave forms represent central aortic wave forms in the newborn (7), we assume that we are allowed to compare our radial artery findings to central recordings in other studies.

Pulsus bisferiens is derived from bis-ferio, which means twice-beating. The earliest reference in print to the pulsus bisferiens is in a Latin edition of Galen's De Pulsibus, published in Paris in 1532. Galen stated that the pulsus bisferiens is characterized by quies media ictus-a central pause in the stroke. Only after the invention of the sphygmograph in 1860 did more accurate information regarding the wave form become available. Since the end of the 19th century pulsus bisferiens has been observed and reported by several authors. The bisferiens pulse has been reported in cases of aortic regurgitation (20-23) and in cases of aortic regurgitation after valvotomy (17). According to Hancock and Abelmann (22), the two peaks may also be prominent enough to produce a bisferiens pulse in anemia and hyperthyroidism. Furthermore, bisferiens pressure pulse is known to exist in hypertrophic obstructive cardiomyopathy (24-26). Bramwell (27) reported that any condition causing a high PP and a low DAP tended to produce a pulse resembling that of aortic incompetence.

It is poorly understood which factors are responsible for the character of a bisferiens pulse, but several hypotheses may be suggested. As shown in Tables 2 and 3 , the timing of $t_{1}$ in the normal wave is not different from the moment of appearance of $t_{1}$ in pulsus bisferiens. During PDA, $\mathrm{P}_{\text {peak1 }}$ may be increased with respect to control (Table 2) due to an increase in stroke volume. However, due to the run-off through the ductus in PDA, this pressure decreases rapidly. The reflected wave from the periphery then may produce an increase in pressure again, resulting in the second peak of the typical wave. Each delay in the return of the reflected wave may generate a twin peaks contour.

Another explanation of the phenomenon is the following. Possibly, the double peaked pressure contour can be explained on the basis of fluid dynamics. An increase in stroke volume during PDA (28-35) may result in an increase in blood velocity. High blood velocity may create a Venturi effect (suction effect) such that pressure energy is reduced relative to the pressure that would be registered if the blood had no kinetic energy, resulting in a temporary pressure decrease coincident with maximum flow. Such an explanation has been advanced by several authors regarding explanation of the pulsus bisferiens in adults $(3,17,36)$. Sabbah et al. (37) and Stein et al. (38) suggested a mechanism based on this fluid dynamic theory with implication of turbulent blood flow. This hypothesis requires that the peak systolic flow velocity occurs at the same time as the cleft between the two peaks. Additional investigations are needed to support or reject this hypothesis.

To support or reject the above mentioned hypotheses, correlation of pressure with data on stroke volume and aortic flow velocity including acceleration time and peak systolic velocity are needed. Another important topic for future research in this field is the influence of mechanical ventilation on the blood pressure wave form. In our study, we were not able to record parameters of the ventilation. Our blood pressure recordings showed that a pulsus bisferiens was present in wave forms both during inspiration and during expiration. Small fluctuations in $\mathrm{SAP}, \mathrm{DAP}$, and MAP were seen in the blood pressure record- 
ings, which were thought to be due to ventilation. Independent on ventilation, the wave forms for analysis in our study were selected at random on the condition that the diastolic value of the beginning of the wave form did not deviate more than $5 \%$ from the end diastolic value. As the influence of ventilation on blood pressure wave forms is rather complex, further studies are needed to describe this influence in detail.

In conclusion, we found that pulsus bisferiens in the radial artery wave of the newborn may be a sign of a hemodynamically significant left-to-right shunt. Therefore, clinicians involved in the care of critically ill newborn infants should be aware of this phenomenon. We recommend to assess ductal patency by echocardiographic examination when a pulsus bisferiens appears in the radial artery wave. Additional investigations are needed to find out which factors are responsible for the character of the bisferiens pulse.

Acknowledgements. The authors thank the staff of the neonatal intensive care unit for the assistance on the ward. We are very grateful to R. J. A. Peters for developing the software application for beat-to-beat blood pressure analysis and to $\mathrm{P}$. Steendijk for statistical help. We acknowledge C. Lasham for English editorial advice.

\section{REFERENCES}

1. O'Rourke MF 1971 The arterial pulse in health and disease. Am Heart $J$ 82:687-702

2. O'Rourke MF, Avolio AP 1980 Pulsatile flow and pressure in human systemic arteries: studies in man and in a multibranched model of the human systemic arterial tree. Circ Res 46:363-372

3. O'Rourke M 1982 Analysis of arterial waves. In: Arterial Function in Health and Disease. Churchill Livingstone, New York, pp 67-76

4. Murgo JP, Westerhof N, Giolma JP, Altobelli SA 1980 Aortic imput impedance in normal man: relationship to pressure wave forms. Circulation 62:105-116

5. Tavel ME 1985 The carotid pulse tracing: its clinical application In: Ryan JD, Perveiler FM (eds) Clinical Phonocardiography and External Pulse Recording, Ed. 4 Year Book Medical Publishers, Chicago, pp 204-223

6. Hack WWM, Westerhof N, Leenhoven T, Okken A 1990 Acccurate measurement of intra-arterial pressure through radial artery catheters in neonates. J Clin Monit 6:211-216

7. Gevers M, Hack WWM, Ree EF, Lafeber HN, Westerhof N 1993 Arterial blood pressure wave forms in radial and posterior tibial arteries in critically ill newborn infants. J Dev Physiol 19:179-185

8. Rudolph AM, Scarpelli EM, Golinko RJ, Gootman NL, New York NY 1964 Hemodynamic basis for manifestations of patent ductus arteriosus. Am Heart J $68: 447-458$

9. Spach MS, Serwer GA, Anderson PAW, Canent RV, Levin AR 1980 Pulsatile aorto-pulmonary pressure-flow dynamics of patent ductus arteriosus in patients with various hemodynamic states. Circulation 61:110-122

10. Serwer GA, Armstrong BE, Anderson PAW 1980 Noninvasive detection of retrograde descending aortic flow in infants using continuous wave Doppler ultrasonography. Implications for diagnosis of aortic run-off lesions. J Pediatr 97:394-400

11. Lees MH, Newcomb JD, Sunderland CO, Droukas P, Reynolds JW 1981 Doppler ultrasonography in evaluation of PDA shunting. J Pediatr 98:852-853

12. Gevers M, van Genderingen HR, Lafeber HN, Hack WWM 1994 Radial artery blood pressure measurement in neonates: an accurate and convenient technique in clinical practice. J Perinat Med. (in press)

13. Fyler DC 1992 Patent ductus arteriosus. In: Fyler DC (ed) Nadas' Pediatric Cardiology. CV Mosby, Philadelphia, p 527

14. Evans N, Moorcraft J 1992 Effect of patency of the ductus arteriosus on blood pressure in very preterm infants. Arch Dis Child 67:1169-1173

15. Ratner I, Perelmuter B, Toews W, Whitfield J 1985 Association of low systolic and diastolic blood pressure with significant patent ductus arteriosus in the very preterm low birthweight infant. Crit Care Med 13:497-500

16. Evans N, Iyer P 1993 Change in blood pressure after treatment of patent ductus arteriosus with indomethacin. Arch Dis Child 68:584-587

17. Fleming PR 1957 The mechanism of pulses bisferiens. Br Heart J 19:519-524

18. Ikram H, Nixon PGF, Fox JA 1964 The haemodynamic implications of the bisferiens pulse. Br Heart J 26:452-459

19. Perloff JK 1987 The Clinical Recognition of Congenital Heart Disease. WB Saunders, Philadelphia, pp 475-477

20. Broadbent W 1899 Pulsus bisferiens. Br Med J 1:75-77

21. Clarke JM 1894 On the pulsus bisferiens of aortic regurgitation. Lancet 2:1529-1531

22. Hancock EW, Abelmann WH 1957 A clinical study of the brachial arterial pulse form, with special reference to aortic valvular disease. Circulation 16:572-581

23. Robinson B 1962 The carotid pulse. Relation of external recordings to carotid, aortic and brachial pulses. Br Heart J 25:61-68

24. Braunwald E, Lambrew CT, Rockoff SD, Ross J, Morrow AC 1964 Idiopathic hypertrophic subaortic stenosis: a description of the disease based upon an analysis of 64 patients. Circulation(suppl IV)3:80

25. Lemke R, Kaltenbach M 1979 The meaning of the systolic progression of the mitral valve for the outflow tract obstruction in hypertrophic obstructive cardiomyopathy. Studies by means of a valve model. Z Kardiol 68:694-699

26. Schulte HD, Losse B 1985 Hypertrophic obstructive cardiomyopathy: surgical treatment and results. Herz 10:102-111

27. Bramwell C 1937 The arterial pulse in health and disease. Lancet $2: 239,301,306$

28. Rudolph AM 1970 The changes in circulation after birth. Their importance in congenital heart disease. Circulation 16:343-359

29. Clyman RI, Roman C, Heymann MA, Mauray F 1987 How a patent ductus arteriosus effects the premature lambs ability to handle additional volume loads. Pediatr Res 22:531-535

30. Clyman RI, Mauray F, Heyman MA, Roman C 1987 Cardiovascular effects of a paten ductus arteriosus in preterm lambs with respiratory distress. J Pediatr 111:579-587

31. Alverson DC, Eldridge MW, Johnson JD, Burstein R, Papile L, Dillon T, Yabek S, Berman W 1983 Effect of patent ductus arteriosus on left ventricular output in premature infants. J Pediatr 102:754-757

32. Mellander M, Larsson LE 1988 Effects of left-to-right ductus shunting on left ventricular output and cerebral blood flow velocity in 3-day old preterm infants with and without severe lung disease. J Pediatr 113:101-109

33. Walther FJ, Kim DH, Ebrahimi M, Siassi B 1989 Pulsed doppler measurement of left ventricular output as early predictor of symptomatic patent ductus arteriosus in very preterm infants. Biol Neonate 56:121-128

34. Hirsimäki H, Kero P, Wanne O, Erkkola R, Makoi Z 1988 Doppler derived cardiac output in healthy newborn infants in relation to physiological patency of the ductus arteriosus. Pediatr Cardiol 9:79-83

35. Lindner W, Seidel M, Versmold HT, Dohleman C, Riegel KP 1990 Stroke volume and left ventricle output in preterm infants with patent ductus arteriosus. Pediatr Res $27: 278-281$

36. Katz LN, Ralli EP, Cheer SN 1928 The cardiodynamic changes in the aorta and left ventricle due to stenosis of the aorta. J Clin Invest 5:205-227

37. Sabbah HN, Blick EF, Anbe DT, Stein PD 1980 Effect of turbulent blood flow on systolic pressure contour in the ventricles and great vessels: significance related to anacrotic and bisferious pulses. Am J Cardiol 45:1139-1147

38. Stein PD, Sabbah HN 1976 Turbulent blood flow in the ascending aorta of humans with normal and diseased aortic valves. Circ Res 39:58-65

\section{APPENDIX}

Diastolic decay time of the wave $(\tau)$ was estimated as follows. Time and pressure of aortic valve closure $\left(t_{c}, p_{c}\right)$ and of diastole $\left(t_{d}, p_{d}\right)$ in the downstroke of the wave were determined.

To find decay time $p_{c}$ and $p_{d}$ can be expressed in an exponential function using the following equations:

and

$$
\mathrm{p}_{\mathrm{c}}=\mathrm{p}_{0} \cdot \mathrm{e}^{-\frac{\mathrm{t}_{\mathrm{c}}}{\tau}}
$$

$$
\mathrm{p}_{\mathrm{d}}=\mathrm{p}_{0} \cdot \mathrm{e}^{-\frac{\mathrm{t}_{\mathrm{d}}}{\tau}} \rightarrow \tau=\frac{\left(\mathrm{t}_{\mathrm{d}}-\mathrm{t}_{\mathrm{c}}\right)}{\ln \left(\mathrm{p}_{\mathrm{c}} / \mathrm{p}_{\mathrm{d}}\right)}
$$

